\title{
O Ensino do genograma no curso de enfermagem
}

\author{
Genogram teaching in nursing curse \\ Enseñanza de genograma en curso de enfermería
}

Marcelo Alexandre Albino Filho ${ }^{1 *}$, Gabriel Mendes Plantier ${ }^{1}$, Thyfany Cricia Cordeiro Alves ${ }^{1}$

\begin{abstract}
RESUMO
Objetivo: Analisar como o ensino do genograma ocorre no curso de Enfermagem. Métodos: Neste estudo foi utilizado uma abordagem qualitativa do tipo descritivo. A amostra foi constituída por estudantes regularmente matriculados nas disciplinas integradas da Atenção Básica no curso de Enfermagem. A análise dos dados foi realizada por meio da análise de conteúdo. Resultados: Foram identificados dois núcleos de sentido: "A importância do Genograma para o Cuidado em Saúde" e "A Semiótica como suporte para Compreensão da Unidade Familiar". Conclusão: Evidencia-se ainda a prevalência do modelo biologicista e ressalta-se a importância de maiores referenciais para embasar a prática em saúde uma vez que a interdisciplinaridade torna-se crucial para a prática em saúde. Além disso, é importante que os cursos na área da saúde estejam organizados de forma a promover sucessivas aproximações e práticas efetivas no que diz respeito ao cuidado familiar, em especial, ao proporcionar a elaboração e fundamentação do uso do genograma para a prática em saúde.
\end{abstract}

Palavras-chave: Enfermagem, Relações familiares, Estudantes.

\begin{abstract}
Objective: Analyze how the teaching of the genogram occurs in the Nursing course. Methods: In this study a qualitative approach of the descriptive type was used, the sample consisted of students regularly enrolled in the integrated disciplines of Primary Care in the Nursing course. Results: Data analysis was performed through content analysis. Two nuclei of meaning were identified: "The importance of the Genogram for Health Care" and "Semiotics as a support for Understanding the Family Unit". Conclusion: The prevalence of the biologicist model is also evident and the importance of greater references to support health practice is emphasized, since interdisciplinarity becomes crucial for health practice. In addition, it is important that courses in the health area are organized in order to promote successive approaches and effective practices with regard to family care, in particular, by providing the elaboration and justification of the use of the genogram for health practice.
\end{abstract}

Keywords: Nursing, Family relations, Students.

\section{RESUMEN}

Objetivo: Analizar cómo se produce la enseñanza del genograma en el curso de Enfermería. Métodos: en este estudio se utilizó un enfoque cualitativo del tipo descriptivo, la muestra consistió en estudiantes matriculados regularmente en las disciplinas integradas de Atención Primaria en el curso de Enfermería. El análisis de datos se realizó a través del análisis de contenido. Resultados: Se identificaron dos núcleos de significado: "La importancia del Genograma para la Atención de la Salud" y "Semiótica como apoyo para la

\footnotetext{
1 Universidade do Oeste Paulista (UNOESTE), Presidente Prudente - SP.

*E-mail: marceloalexandrealbino@hotmail.com
} 
comprensión de la Unidad Familiar". Conclusión: La prevalencia del modelo biologista también es evidente y se enfatiza la importancia de mayores referencias para apoyar la práctica de la salud, ya que la interdisciplinariedad se vuelve crucial para la práctica de la salud. Además, es importante que se organicen cursos en el área de la salud para promover enfoques sucesivos y prácticas efectivas con respecto a la atención familiar, en particular, proporcionando la elaboración y justificación del uso del genograma para la práctica de la salud.

Palabras clave: Enfermería, Relaciones familiares, Estudiantes.

\section{INTRODUÇÃO}

No Brasil, a Reforma Sanitária em 1970, a promulgação da Constituição de 1988, o Programa de Agentes da Saúde (PACS) em 1991 e o Programa de Saúde da Família em 1994, estruturam a Atenção Básica $(A B)$ que é definida como um conjunto de atividades de saúde, no âmbito individual e coletivo, que envolve a promoção e proteção da saúde, a prevenção de agravos, diagnóstico, tratamento, reabilitação, redução de danos e manutenção da saúde (BRASIL, 2013).

A Estratégia de Saúde da Família (ESF) elege a família e seu espaço social como núcleo básico central no atendimento à saúde, bem como a superação da fragmentação dos cuidados, o que corrobora com as necessidades de compreender não só o indivíduo, mas, também, o modo como vive e interage com o ambiente (BRASIL, 2013).

Desta forma, o genograma é uma potente ferramenta para compreensão da unidade familiar, podendo ser usado como instrumento de promoção do cuidado em saúde, para o entendimento mútuo entre a equipe de saúde e a pessoa, como recurso diagnóstico e como veículo para construção de aliança terapêutica. Possui em sua constituição símbolos, em forma de figuras geométricas, que representam a unidade familiar estruturada no modelo genealógico (BRASIL, 2013). Desta forma, permite visualizar a família como um todo e as relações existentes entre os membros que a constitui. Por tratar-se de representações simbólicas, a semiótica é uma metodologia importante que pode ser aplicada para melhor compreensão desta ferramenta (SANTAELLA L, 2016).

A Semiótica Perciana pertence as ciências normativas e dada sua importância ao domínio da cognição humana, pode ser considerada uma metodologia. Assim, deve-se atentar para que seu uso ocorra de forma profunda e multidimensional. Santaella $L$ (2016) afirma que é possível extrair estratégias metodológicas para leitura e análise de processos empíricos por meio dos tipos de signos e suas misturas sígnicas. Além disso, o genograma pode ser usado em uma variedade de áreas de atuação, além da terapia familiar, sendo inegável seu caráter imutável de identificação de padrões que são formados e de sua transmissão intergeracional (MACEDO RMS, 2014).

Entretanto, o uso do genograma por profissionais da saúde, em especial, nos serviços de saúde da atenção básica, ainda ocorre de forma discreta. Neste sentido, é necessário investir na formação acadêmica de profissionais da saúde para que, cada vez mais, esta ferramenta possa ser incorporada na prática da saúde e utilizada como recurso terapêutico para promoção do cuidado (BORGES CD et al., 2015).

Assim, é importante compreender como o genograma tem sido ensinado nos cursos de graduação em saúde, em especial, no Curso de Enfermagem, uma vez que, o Enfermeiro é um dos profissionais habilitados para identificar os fatores que contribuem para um desequilíbrio no processo saúde-doença da unidade familiar. Portanto, o objetivo deste estudo é analisar como ocorre o ensino do genograma no Curso de Enfermagem.

\section{MÉTODOS}

Trata-se de um estudo de abordagem qualitativa. A amostra do estudo foi composta por estudantes de enfermagem do curso de Enfermagem da Universidade do Oeste Paulista - UNOESTE, campus de 
Presidente Prudente. Foram selecionados aleatoriamente por meio da disponibilidade dos participantes, pois o único critério de inclusão era estarem regularmente matriculados nos $4^{\circ}$ e $7^{\circ}$ períodos do curso, momento em que ocorre o ensino e o uso do genograma. A quantidade de participantes foi determinada por meio da saturação das respostas, definida como a suspensão de inclusão de novos participantes quando os dados apresentam redundância ou repetição (Fontanella BJB et al., 2008).

Os estudantes foram abordados pelos autores por meio de uma entrevista semiestruturada e indagados quanto a importância do genograma para o cuidado em saúde; se durante a formação profissional, a maneira como seu uso foi ensinada favoreceu o aprendizado, bem como, as dificuldades existentes em seu uso no dia-a-dia. A entrevista foi utilizada pois, ao mesmo tempo em que permite o relato espontâneo, delimita a temática a ser explorada, atingindo as necessidades deste estudo. $O$ tempo das entrevistas variou de 15 a 20 minutos.

As entrevistas foram analisadas por meio da análise de conteúdo, que consiste em um conjunto de técnicas de análise, por meio de procedimentos sistemáticos e objetivos de descrição do conteúdo, que permitam a inferência de conhecimentos relativos às condições de produção dos relatos (BARDIN F, 2011).

Os entrevistados que aceitaram participar da pesquisa assinaram o Termo de Consentimento Livre e Esclarecido, em respeito aos princípios éticos. A pesquisa foi aprovada pelo Comitê de Ética em Pesquisa (CEP) e do Comitê Assessor de Pesquisa Institucional (CAPI) da Universidade do Oeste Paulista - Campus de Presidente Prudente com parecer número 3.193.138.

\section{RESULTADOS E DISCUSSÃO}

Os estudantes regularmente matriculados nos períodos do Curso de Enfermagem aos quais exercem a prática profissional na Atenção Básica totalizaram 49 estudantes (32,8\%). A análise dos dados permitiu identificar dois núcleos de sentido: "A importância do Genograma para o Cuidado em Saúde" e "A Semiótica como suporte para Compreensão da Unidade Familiar".

\section{A importância do Genograma para o Cuidado em Saúde}

O ensino do genograma, na Instituição de ensino aqui estudada, acontece quando os acadêmicos executam suas atividades teóricas e práticas na Atenção Básica. Isto acontece porque subtende-se que é um instrumento específico para compreensão da unidade familiar, sendo este, um recurso aos profissionais que ali atuam.

A inserção dos estudantes acontece de forma que vivenciam a rotina do processo de trabalho, a fim de que, por meio de metodologias ativas de aprendizagem, busquem o conhecimento necessário para implementar intervenções de saúde em âmbito individual e coletivo (UNOESTE, 2015).

Desta forma, o genograma é incluso como parte da sistematização da coleta de dados no Processo de Enfermagem, de forma a auxiliar na identificação das necessidades de saúde da família acompanhada. $O$ modelo econômico globalizado e as políticas de saúde atuais têm levantado a necessidade em avaliar e acompanhar a qualidade dos serviços de saúde. O Processo de Enfermagem como metodologia científica do enfermeiro deve ser sistematizado e planejado para que os dados coletados se tornem subsídios para a identificação dos estados de saúde da família e permita a avaliação da qualidade do serviço (TANNURE MC e PINHEIRO AM, 2015).

A literatura internacional corrobora com o uso do genograma como instrumento para coleta de dados durante o Processo de Enfermagem. No Chile, autores como Giordano DP et al (2015) e Montero-Ossandon L (2010) reiteram que o genograma é uma representação gráfica da composição familiar, onde são registrados os membros que constituem a família, bem como suas relações.

Na França, Reid A (2016) junto com estudantes do curso de psicologia, compreendem que o genograma é uma importante ferramenta, utilizada por profissionais, que ajuda a compreender a constituição familiar do sujeito, de forma a ajudar na compreensão do inconsciente coletivo e os segredos familiares, ambos conceitos trabalhados por grandes pensadores como Sigmund Freud. 
Um estudo realizado na Tailândia associa as altas taxas de mortalidade por acidente vascular encefálico com a falta de investimentos em prevenção. Apontam o uso do genograma como uma ferramenta pra identificação dos indivíduos com necessidade de intervenção prévia e como guia para a criação de programas de educação preventiva (SINGHA-DONG N e BIGELOW A, 2017). Assim, após o exercício da prática profissional, os acadêmicos mencionam que o genograma é importante para identificar patologias de caráter hereditário.

\footnotetext{
"Visa salientar não apenas as características da área genealógica, mas a prevalência de patologias com características hereditárias". (E3)

"O genograma fornece um olhar sobre as predisposições para doenças $e$ vulnerabilidades". (E6)
}

Para compreender a finalidade e importância do uso do genograma para a prática em saúde é necessário aprofundar reflexões sobre as origens do cuidado familiar, bem como os referenciais clássicos e raciocínio que sustentam e estruturam seu uso. Além disso, o estudante de Enfermagem deve reconhecer o genograma como ferramenta para raciocínio clínico na tomada de decisão diagnóstica no Processo de Enfermagem; é notório na fala dos estudantes o caráter reducionista e biologicista sobe o uso do genograma durante a formação acadêmica (MCEWEN M e WILLS EM, 2016).

Associar o genograma apenas ao caráter hereditário remete-o ao darwinismo clássico, que explana, de forma categórica, condições do ambiente que influenciam diretamente nos seres vivos, por meio da variação correlativa, uso e desuso dos órgãos e os efeitos do hábito. Entretanto, é importante ampliar o olhar, de forma a notar e aumentar o rigor de observação sobre o humano e de suas relações com os seres da mesma espécie e com o ambiente (DARWIN C, 2017).

O ensino fragmentado de disciplinas corrobora para a persistência do modelo biomédico em saúde. As especialidades médicas, ainda muito fortes nos centros de saúde, são cobiçadas por grande parte da população, que age culturalmente em busca de cura e resoluções pontuais para os problemas de saúde.

Neste sentido, faz-se necessário também citar os fatores sociais, econômicos, culturais, étnicos/raciais, psicológicos e comportamentais que influenciam a ocorrência de problemas de saúde e seus fatores de risco na população, denominados como os Determinantes Sociais da Saúde - DSS (BUSS PM e PELLEGRINI FILHO A, 2007).

Uma vez elencada como núcleo central de atendimento à saúde, a família passa a ser o foco das ações em saúde na $A B$. Porém, a definição de família é de difícil conceituação. Murray Bowen, psicoterapeuta e psicanalista (1913-1990), expõem em suas obras elementos existentes nas relações familiares. O primeiro conceito abordado por Bowen é o da aliança triangular. A relação entre duas pessoas, em algum momento, encontrará um nível de ansiedade a tal ponto de necessitar de um terceiro elemento que atuará como dissipador do estresse existente, reequilibrando as relações entre os elementos que constituem a família (CERVENY CMO, 2014).

O segundo conceito trabalhado por Bowen é o da massa indiferenciada do ego familiar; os fatos que acometem uma geração da família se repetem na geração seguinte, porém ressalta que o comportamento dos indivíduos pode ser evidenciado em formas distintas de repetição. Por fim, Bowen afirma que existem elementos de coesão que controlam o sistema emocional familiar. Tais elementos dizem respeito as convicções, filosofias, princípios de vida e sentimentos que definem a identidade familiar dos indivíduos (CERVENY CMO, 2014).

Exposto o caráter para além do aspecto biológico e a importância do uso do genograma para o cuidado familiar, é crucial que os conceitos trabalhados por Bowen sejam inclusos nas disciplinas de saúde da família nas Instituições de ensino superior, de forma que, os estudantes compreendam que a prática da saúde coletiva extrapola o reducionismo ainda vigente na área da saúde.

Estudos internacionais evidenciam que o uso do genograma na prática da saúde apoia uma abordagem holística e contribui para a prevenção de doenças. Em uma revisão sistemática, Piasecka K, et al. (2018) 
expõe que, além de seu caráter holístico, o genograma pode ser utilizado como uma ferramenta de pesquisa, o que facilita enunciar diagnósticos de enfermagem, possibilitando um atendimento personalizado. Aspecto este que também deve ser incluso nas disciplinas curriculares dos cursos de Enfermagem.

Outra questão que deve ser discutida é a amplitude das teorias de enfermagem que sustentam o cuidado. A ciência da enfermagem debatida nas teorias é descrita como um conhecimento substantivo que tem foco no processo humano-universo-saúde, já caracterizando um olhar distante do modelo biológico, reducionista e fragmentado (MCEWEN M e WILLS EM, 2016).

Fundamentado nos modelos de enfermagem, reconhecidos como Teorias de Enfermagem, o raciocínio clínico do enfermeiro deriva de processos sistemáticos e conceitos próprios; o genograma pode facilitar o entendimento do enfermeiro para avaliar, reconhecer e antecipar as condições de saúde, processos de vida, ou vulnerabilidades da pessoa, família ou comunidade (HERDMAN,2018).

Atrelado à análise e reconhecimento destas condições, os diagnósticos de enfermagem representam os conceitos ou fenômenos sensíveis à enfermagem que caracterizam o impacto da idade, espiritualidade, cultura, relações familiares/sociais e as experiências de vida que podem afetar as respostas às condições de saúde. Desta forma o genograma é uma ferramenta que pode auxiliar neste processo de análise (MCEWEN M e WILLS EM, 2016).

Desta forma, é importante que a academia invista, cada vez mais, na formação de profissionais para exercerem a prática profissional em saúde na atenção básica, de forma que o genograma não seja apenas mais uma ferramenta, mas sim, um importante recurso diagnóstico e terapêutico associado aos modelos de enfermagem.

\section{A Semiótica como suporte para Compreensão da Unidade Familiar}

Os estudantes mencionaram que o uso do genograma na prática profissional em saúde durante o curso de Enfermagem é dificultada pela falta de clareza, por parte do examinador, durante a coleta de dados:

"Maior dificuldade é a coleta de dados precisa para construção eficaz do mesmo" (E32)

"Coleta de dados muitas vezes insuficientes com dificuldades com pacientes mais idosos ou desorientados". (E8)

Além disso, relatam que o ensino do genograma durante o curso ocorreu de forma superficial com consequente fragilidade em sua elaboração:

"Aprendemos muito superficialmente e temos muitas dificuldades ao executá-lo." (E29)

"Para mim, o genograma não foi ensinado corretamente durante o curso, mas acredito que ele favorece no cuidado na hora de pensar sobre as famílias e elaborar o plano de cuidado. (E28)

As fragilidades do ensino do genograma são multidimensionais. Primeiramente, ele é pouco valorizado nos cenários da saúde; o estudante não vivencia os profissionais o utilizarem no cuidado familiar; a forma como é abordado na academia é pontual e com pouco aprofundamento teórico; poucos profissionais sabem elaborá-lo de forma a convergir com seu real objetivo.

De acordo com Pícoli RP e Cazola LHO (2017), o genograma é um instrumento que permite ao profissional de saúde visualizar quem são os membros que constituem a família, bem como os vínculos consanguíneos ali existentes e padrões de organização familiar e comportamentais que são importantes para o processo saúde-doença.

Além disso, Nogueira APF, et al. (2017) afirmam que, com o genograma, é possível projetar medidas ou programas que auxiliam o profissional a adotar estratégias de forma a considerar as situações específicas 
de cada membro da família. Assim, é importante investir na formação profissional oportunizando sucessivas aproximações ao considerar que os estudantes necessitam treinar habilidades de comunicação e raciocínio.

Outro aspecto muito importante mencionado pelos estudantes diz respeito as formas de elaboração do genograma:

\section{"Minha maior dificuldade é ao usar as simbologias na hora de ilustrar" (E36)}

O genograma é elaborado por meio do uso de símbolos convencionados que representam a unidade familiar. Nele, também é possível representar as relações entre os indivíduos e alguns determinantes sociais de saúde. Por ser constituído de símbolos, que são meios de linguagem, a Semiótica pode contribuir como aprofundamento teórico para elaboração do genograma, bem como para compreensão das relações semióticas ali existentes que, permitem ao examinador, maior propriedade para identificar as necessidades de saúde da família avaliada.

Peirce CS (2017) sempre buscou o conhecimento dos métodos e dos fundamentos lógicos nas diversas áreas das ciências. Desta forma, a Semiótica Peirceana é embasada na fenomenologia, uma quase-ciência que investiga como as coisas se apresentam à mente, havendo três elementos formais e universais que se apresentam em qualquer fenômeno: a primeiridade está relacionada ao acaso, no sentido aqui de possibilidade; a secundidade ao conflito e a dúvida; e a terceiridade à generalidade.

Desta forma, Santaella $L$ (2016) afirma que o signo é algo que se apresenta à mente, ligado àquilo que o indica, se refere ou representa, causando um efeito ao seu possível intérprete. Como exemplo, o genograma é um signo que representa uma família (objeto), produzindo um significado no avaliador que, permitirá, assim, uma compreensão ampla do processo saúde-doença que acomete os indivíduos ali representados.

Assim, para Peirce CS (2017) todo signo pode ser analisado em si mesmo, naquilo a que se refere e nos efeitos que produz nos receptores, caracterizando, assim, a natureza tríadica de todo signo. Ou seja, como explica Santaella CS (2016), todo signo inclui uma significação, uma objetivação e uma interpretação.

Importante salientar que o conhecimento dos sistema de signos, bem como do contexto sociocultural no qual se situa, permite compreender o contexto no qual a mensagem é transmitida ao receptor. Portanto, não basta somente saber estruturar o genograma, mas também considerar o contexto no qual a família se encontra, levando em consideração as relações de significação, objetivação e interpretação que se estabeleceram durante a coleta dos dados.

Além disso, há três relações que o signo pode estabelecer com o objeto. Se a relação for de caráter qualitativo, tem-se um ícone; se for existente, um índice; e se for uma lei, um símbolo. Santaella L (2016) explicita que os signos só podem se reportar a algo quando evoca aquilo a que ele se refere, caracterizando, assim, o objeto imediato.

Exemplificando, o genograma pode ser considerado um caso índice, pois representa uma configuração familiar. Desta forma, o objeto imediato do índice demonstra a capacidade de indicar a existência da família, porém o genograma em si, não é a família, havendo uma conexão existencial entre o objeto e seu índice.

Há também três passos para que a interpretação ocorra. $O$ primeiro passo configura-se como o interpretante imediato, ou seja, o potencial para que algo seja interpretado tão logo encontre um intérprete. O segundo passo é o interpretante dinâmico, que diz respeito a dimensão psicológica do interpretante, pois se trata do efeito singular que o signo produz em cada intérprete em particular. O terceiro e último passo é o interpretante final que condiz ao resultado interpretativo. Desta forma, os níveis do interpretante incorporam elementos lógicos, racionais, emotivos, sensórios como parte do processo interpretativo (SILVEIRA LFB, 2007).

Para uma primeira leitura, a Semiótica parece ser de difícil compreensão. Assim como toda apropriação do conhecimento, sucessivas aproximações são importantes para que o leitor possa, cada vez mais, apropriar-se do raciocínio semiótico. A fim de atingir o objetivo deste estudo, esta primeira aproximação é suficiente para sustentar, um pouco mais, a elaboração do genograma nos cursos na área da saúde. 
Santaella L (2016), em seu livro Semiótica Aplicada, explora como a Semiótica pode ser aplicada em várias áreas do conhecimento, como a publicidade, arte, mídia, vídeos, literatura, etc. A tentativa aqui foi de também aplicá-la na área da saúde. Porém, ainda se trata de uma primeira aproximação.

\section{CONCLUSÃO}

O estudo possibilitou compreender a percepção de acadêmicos do Curso de Enfermagem sobre o uso do genograma durante o exercício da prática profissional na Atenção Básica. Destaca-se a importância e dificuldades encontradas por eles no uso desta ferramenta. Desta forma, a inserção de mais referenciais para embasar a prática em saúde é cada vez mais necessária e importante, de forma que o genograma não seja apenas mais uma ferramenta, mas sim, um importante recurso diagnóstico e terapêutico. Além disso, é importante que os cursos na área da saúde estejam organizados de forma a promover sucessivas aproximações e práticas efetivas no que diz respeito ao cuidado familiar, em especial, ao proporcionar a elaboração e fundamentação do uso do genograma para a prática em saúde.

\section{REFERÊNCIAS}

1. BARDIN F. Análise de Conteúdo. São Paulo: Edições 70, 2011.

2. BORGES CD, et al. Genograma e atenção básica à saúde: em busca da integralidade. Revista Psicologia e Saúde, 2015; 7(2): 133-141.

3. BRASIL. Ministério da Saúde. Caderno de Atenção Domiciliar. Brasília - DF, 2013.

4. BUSS PM, PELLEGRINI FILHO A. A Saúde e seus determinantes sociais. Rev Saúde Coletiva, 2007; 17(1).

5. CERVENY CMO. O livro do genograma. São Paulo: Roca, 2014.

6. DARWIN C. A origem das espécies: por meio da seleção natural. São Paulo: Lafonte, 2017.

7. FONTANELLA BJB, et al. Amostragem por saturação em pesquisas qualitativas em saúde: contribuições teóricas. Cad Saude Publica (Rio de Janeiro). 2008; 24(1):17-27.

8. GIORDANO DP, et al. Processo de enfermería en un studio de familia de persona adulta mayor en atencíon primaria de salud. Enfermería Universitaria. 2017;14(1):67-75.

9. HERDMAN TH, KAMITSURU S. Diagnósticos de enfermagem da NANDA: definições e classificação 2018-2020. 11 ed. Porto Alegre: Artmed, 2018.

10. MACEDO RMS. Genograma Origens e Usos. In: Cerveny CMO. O Livro do Genograma. São Paulo: Roca, 2014; $248 \mathrm{p}$.

11. MCEWEN M, WILLS EM. Bases teóricas de enfermagem. $4^{\circ}$ ed. Porto Alegre: Artmed, 2016.

12. MONTERO-OSSANDON L. Evaluación del funcionamiento familiar: Genograma y APGAR familiar. In: DoisCastellón A, Montero-Ossandón L, editores. Manual de atención de familias para profesionales de la salud. Santiago, Chile: Ediciones UC; 2012, p. 117-35.

13. NOGUEIR-+8952

14. $30 A$ APF, et al. A importância do uso do genograma para compreensão da dinâmica familiar. Rev enferm UFPE on line, $2017 ;$ 11(12): 5110-5.

15. PEIRCE CS. Semiótica. São Paulo: Perspectiva, 2017.

16. PIASECKA K, et al. Genograms in Nursing Education and Practice a Sensitive but Very Effective Technique: A Systematic Review. J Community Med Health Educ, 2018, 8(6).

17. PÍCOLI RP, CAZOLA LHO. Genograma na formação médica: percepção do estudante. Rev. Bras. Pesq. Saúde, 2017; 19(3): 92-99.

18. REID A. LA psychogénéalogie et son histoire. Soins Psychiatrie, 2016 37(304).

19. SANTAELLA L. Semiótica aplicada. São Paulo: Cengage Learning, 2016.

20. SILVEIRA LFB. Curso de Semiótica Geral. São Paulo: Quartier Latin, 2007.

21. SINGHA-DONG N, BIGELOW A. SUT Stroke Specifi c Genogram: Application of Genogram on Screening for Individual at Risks of Stroke in Rural Thai Community. Glob J Medical Clin Case Rep. 2017; 4(3): 058-064.

22. TANNURE MC, Pinheiro AM. SAE: Sistematização da assistência de enfermagem: guia prático. $2^{\circ}$ ed. Rio de Janeiro: Guanabara Koogan, 2015.

23. UNIVERSIDADE DO OESTE PAULISTA - UNOES TE. Projeto Político Pedagógico do Curso de Enfermagem. Presidente Prudente, 2015.0. 